\title{
Episiotomy site endometriosis: a rare case report
}

\author{
Fatima Usmani, Rashmi Gupta*
}

Department of Obstetrics and Gynecology, GSVM Medical College, Kanpur, Uttar Pradesh, India

Received: 03 November 2018

Accepted: 14 May 2019

\section{*Correspondence: \\ Dr. Rashmi Gupta, \\ E-mail: drrashmigupta14@gmail.com}

Copyright: (C) the author(s), publisher and licensee Medip Academy. This is an open-access article distributed under the terms of the Creative Commons Attribution Non-Commercial License, which permits unrestricted noncommercial use, distribution, and reproduction in any medium, provided the original work is properly cited.

\begin{abstract}
Endometriosis is defined as the presence of endometrial tissue apart from its usual location. Scar endometriosis is an infrequent type of extra pelvic endometriosis. Viable decidual endometrial cells are likely to be transplanted in the episiotomy wounds during normal delivery and subsequent growth may occur. We present here a case of 22 year old female with perineal endometriosis at the episiotomy site. The clinical, operative and pathological findings are reported.
\end{abstract}

Keywords: Episiotomy, Endometriosis, Episiptomyendometrisis, Perineal endometriosis, Painful scar, Scar endometriosis

\section{INTRODUCTION}

Endometriosis is defined as the presence of functional endometrial tissue outside the uterine cavity. ${ }^{1}$ Endometriosis occur in $5-10 \%$ of all women often resulting in severe dysmenorrhoea and infertility. Although most frequently found in pelvis extra-pelvic sites may range from lungs to extremities. Incisional scar after gynaecological surgery and caesarean section is a relatively uncommon disease, accounting approximately $1 \%$ of all cases out of which perineal scar endometriosis incidence is reported to be $0.3 \%$ to $1 \% .^{1-3}$

This entity often leads to mis-diagnosis and delayed treatment owing to its vague clinical presentation. The diagnosis is frequently made by surgical exploration and histo-pathological evaluation of excised tissue. Authors have present here a case of 22 year old female with perineal endometriosis at the episiotomy site. Viable decidual endometrial cells are likely to be transplanted in the episiotomy wounds during normal delivery and subsequent growth may occur. Surgical exploration and wide excision of the episiotomy site was done. Postoperative period was uneventful. The clinical, operative and pathological findings are reported.

\section{CASE REPORT}

A 22 year old female patient presented with cyclical pain and swelling in the perineal area during menses since 1 year. She was symptom free in between the menses. She had delivered a male baby 4 years back in which episiotomy was given during delivery.

\section{Examination}

perineal skin was normal on inspection with no visible swelling, scar or irregularity. A tender, irregular, hard nodule measuring $2 \times 3 \mathrm{~cm}$ was present in left perineal region over the site of the previous episiotomy scar. Per speculum and per vaginal examination was normal. She consulted a local practitioner who gave her antibiotics and analgesics. Her complaints were not relieved so she came to the outpatient clinic at GSVM Medical College. 


\section{Investigation}

A trans-vaginal Ultrasound was done which revealed a bilobed hypoehoic lesion noted at the lower most part of vulva with subtle left sided predominance measuring $26.5 \times 2.5 \mathrm{~mm}$ and $17.2 \times 2.5 \mathrm{~mm}$ ? Infective focus? Endometriotic deposit with subtle increased attendant vascularity.

\section{Treatment}

Wide excision of the scar with the nodule was done and sent for histopathological examination (Figure 1).

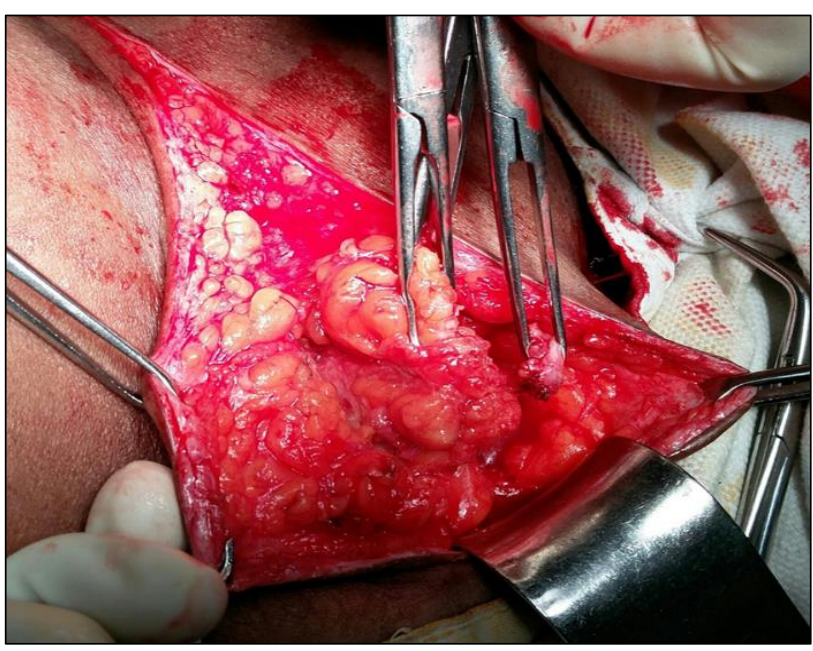

Figure 1: Endometrioic nodule on surgical exploration.

\section{Gross examination}

Gross examination was greyish white, soft to firm and measured $2 \times 1.5 \mathrm{~cm}$.

\section{Histopathology findings}

Sections revealed keratinised, hyperplastic stratified squamous epithelial lining. Underlying fibrocollagenous stroma shows few endometrial gland with scanty stroma, multiple hair follicle, pilosebaceous unit, multiple small sized proliferating thin walled blood vessels, subcutaneous fatty tissue, focal areas of dense inflammatory infiltrates comprising of lymphocytes, macrophages, neutrophils and one cystic space lined by low cuboidal to flattened epithelium, filled with haemorrhage and inflammatory infiltrate comprising of neutrophils and macrophages. The histopathological features were consistent with scar endometriosis with chronic inflammation at the episiotomy site (Figure 2 and 3).

\section{Follow up}

The postoperative period was uneventful. The patient was discharged on the third postoperative day. 1 year after the surgery patient is symptom free with no signs of recurrence and discomfort.

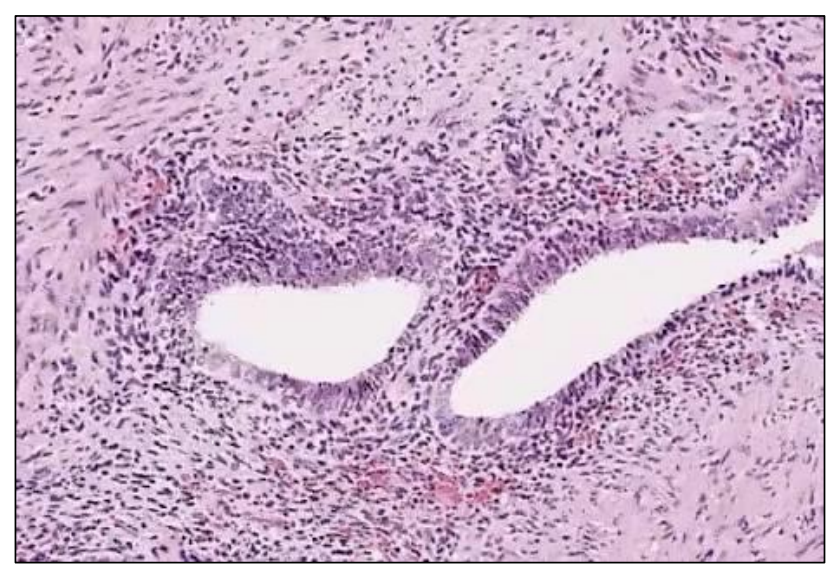

Figure 2: Histopathological slide of endometritic nodule.

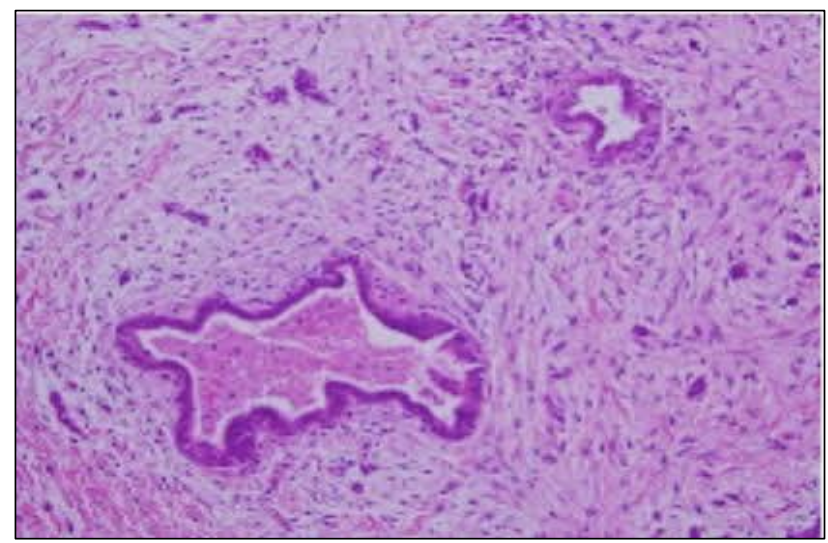

Figure 3: Histopathological slide showing endometrial gland and stroma.

\section{DISCUSSION}

Scar endometriosis is a rare entity with the estimated incidence being 0.03-0.15\% of the endometriosis cases. ${ }^{4}$ Episiotomy scar endometriosis was estimated to be 0.06$0.07 \%$. Owing to its rarity it is not often considered in the differential diagnosis of perineal masses which leads to its delayed diagnosis.

Very few visible signs are present on local inspection of the perineum like there is no discolouration of the perineal skin, no local swelling seen on inspection or periodic leakage of dark coloured fluid.

In some cases, bloody discharge oozing out from the scar has been reported. ${ }^{5}$ The tender nodule and cystic swelling could be felt only on deep palpation and many a time a hurried examination in the outpatient can miss it. Diagnosis can be confirmed by Ultrasound (transperineal, trans-vaginal and endo-vaginal sonography). MRI and CT can also be helpful. 
USG is the most common modality to evaluate suspected endometriosis. However, it is applicable only to the evaluation of endometriotic cysts; detection of adhesions or implants. Endometriomas can have a variety of ultrasound appearances. Majority exhibit low level internal echoes, with classic endometrioma being described as a homogenous, hypoechoic focal lesion as was there in this case. ${ }^{6}$ In rare cases they may be anechoic. They may be unilocular or multilocular. Diffuse wall thickening, wall nodularity and echogenic foci within the cyst wall have been observed. Patel et al, found that $20 \%$ of the endometriomas had solid appearing wall nodularity, a feature classically associated with neoplasia. Echogenic wall foci differ from wall nodularity and are an important discriminating feature. These deposits are more echogenic and smaller than true wall nodules. Study by Patel et al, showed that $35 \%$ of endometriomas demonstrated hyperechoic wall foci, compared with $6 \%$ of non-endometriomas.

MR imaging is more specific than other non-invasive techniques. T1 and T2 shortening that occurs due to high viscosity, high concentrations of protein, and degraded blood products. ${ }^{7}$

Ca 125 has also been measured in cases of perineal endometriosis. It is a good test but negative test does not exclude endometriosis. However, it was raised only in $6.7 \%$ of patients. ${ }^{7}$

Patil et al, studied 17 cases of extrapelvic endometriosis in a time span of 15 years and found a total of three cases of episiotomy scar endometriosis. ${ }^{8}$ Luterek et al, concluded that a wide excision on is mandatory as it is the only way to prevent recurrence. ${ }^{9}$ To prevent recurrence, various authors have reported using the gonadotropin-releasing hormone analogue with benefits. Preoperative gonadotropin-releasing hormone analogue has also been used to shrink a large mass prior to excision to conserve neighbouring structures like the anal sphincter. In case of continual recurrence, possibility of malignancy should be kept in mind. ${ }^{10}$

\section{CONCLUSION}

Scar endometriosis is a rare entity with the estimated incidence being $0.03-0.15 \%$ of the endometriosis cases. Episiotomy scar endometriosis was estimated to be 0.06$0.07 \%$. Owing to its rarity it is not often considered in the differential diagnosis of perineal masses leads to its delayed diagnosis. In perineal endometriosis, there is a very high frequency of recurrence and also a propensity for malignant change, though rare. Therefore, exploration and excision of the endometriotic mass should be performed under general anaesthesia. Wide excision with a $0.5-1 \mathrm{~cm}$ cuff of surrounding healthy tissue should be removed.

\section{Funding: No funding sources \\ Conflict of interest: None declared \\ Ethical approval: Not required}

\section{REFERENCES}

1. Gauna BRD, Rodriguez D,Cabre S, Callejo J. A Case of Endometrisis in episiotomy scar with anal sphincter involvement. International J Clinical Med. 2011;2(5):624-6.

2. Goel P, Sood SS, Dalal A, Romilla. Caesarean Scar Endometriosis: Report of two cases. Indian J Med Sci. 2005;59(11):495-8.

3. Sharma N, Theik JL, Rituparna D, Mishra J, Singh A. Incisional Endometriosis: A rare case of painful scar. J Midwifery Reproductive Health. 2017;5(2):927-9.

4. Francica G, Giardiello C, Angelone G, Cristiano S, Finelli R, Tramanto G. Abdominal wall endometriosis near cesarean delivery scars. J Ultrasound Med. 2003;22(10):1041-7.

5. Salamalekis E, Vasiliadis TX, Kairi P. Perineal endometriosis. Int J Gynaecol Obstet.1990;2013;31(1)-75-80.

6. Patel MD, Feldstein VA, Chen DC, Lipson SD, Filly RA. Endometriomas: diagnostic performance of US. Radiology. 1999;210(3):739-45.

7. Togashi K, Nishimura K, Kimura I, Tsuda Y, Yamashita K, Shibata T, et al. Endometrialcysts: Diagnosiswith MR imaging. Radiology. 1991;180(1):73-8.

8. Patil BS, Tripathi JB, Patil FB. Extrapelvic Endometriosis: A study of 17 cases. J South Asian Fed Obster Gynecol. 2012;4(1):32-4.

9. Luterek K, Barcz E, Bablok L. Giant recurrent perineal endometriosis in an episiotomy scar- a case report. Ginekol Pol. 2013;84(8):726-9.

10. Park SW, Hong SM, Wu HG, Ha SW. Clear cell carcinoma arising in a caesarean scar endomrtriosis. J Korean Med Sci. 1999;14(2):217-9.

Cite this article as: Usmani F, Gupta R. Episiotomy site endometriosis: a rare case report. Int J Reprod Contracept Obstet Gynecol 2019;8:2898-900. 